\title{
O MOMENTO ATUAL DO SUS... A OUSADIA DE CUMPRIR E FAZER CUMPRIR A LEI *
}

\author{
Gilson de Cassia Marques Carvalho * *
}

\section{AS RAÍZES DO SUS}

Não se pode falar de Sistema Único de Saúde, sem antes tentar resgatar uma trajetória de, no mínimo, 30 anos atrás. O que hoje denominamos de SUS tem raízes profundas nos textos dos relatórios das últimas Conferências Nacionais de Saúde, que de alguma maneira traduziram o que à época se pensava.

O Ministro da Saúde, Wilson Fadul, em 1963, na III Conferência Nacional de Saúde já levantava a bandeira da Municipalização dos Serviços de Saúde. O pensamento de uma reforma no Sistema de Saúde foi crescendo. Tiveram papel preponderante no desenvolvimento destas novas idéias os Departamentos de Medicina Preventiva e Social de algumas Escolas Médicas. Com projetos especiais foram criando uma nova mentalidade voltada à integralidade das ações de saúde, aos serviços hierarquizados, com assistência

* Palesta realizada na Faculdade de Saúde Pública da Universidade de São Paulo, em abril de 1993.

* Ex-Secretário de Saúde do Município de São José dos Campos. Diretor do Departamento do SUS/SAS do Ministério da Saúde. 
integral às pessoas e outras premissas mais. Algumas universidades, e aqui vale lembrar a Faculdade de Saúde Pública da USP, que dando resposta a uma proposta do então Secretário Estadual de Saúde de São Paulo, Walter Leser, iniciou cursos de formação de uma nova leva de sanitaristas com outro tipo de visão da realidade. Igualmente importantes foram os departamentos de Medicina Social da UNICAMP, da UERJ e a Escola Nacional de Saúde Pública da FIOCRUZ. Todos formadores de opinião e que levaram consigo ao pensamento e luta inúmeros profissionais.

Surgiram movimentos organizados como o Cebes em 1976 que reuniu profissionais de Saúde das mais diferentes áreas e iniciou uma discussão sobre um novo sistema de saúde. Outras associações como ABRASCO, de Saúde Comunitária, a Associação dos Médicos Sanitaristas, Associação Paulista de Saúde Pública e outras formaram um corpo de pessoas lutando por um sistema de saúde mais justo e igualitário.

Neste mesmo tempo movimentos populares como as Comunidades Eclesiais de Base, as Sociedades Amigos de Bairro e outras Associações de Moradores, Sindicatos de Trabalhadores, tomaram a saúde como objeto de discussão em seus fóruns. Nisto, em 1976, assumem as prefeituras alguns prefeitos, que colocaram como meta de seus governos voltarem-se para o social fugindo do modelo então vigente de "Prefeituras tocadoras de obras". Estas Prefeituras, onde se destacam Campinas, Niterói, Londrina, Rezende, São José dos Campos, Lages, montaram suas redes básicas de serviços de saúde e seus serviços de emergência. A maioria destes serviços se desenvolveu com ampla participação comunitária. Os recursos alocados por estas Prefeituras na área de Saúde foram recursos próprios, sem nenhuma ajuda dos governos federal ou estaduais. Foi o único dinheiro novo que se colocou na saúde nos últimos anos, 
independente de qualquer reforma fiscal. Foi uma resposta formal dos administradores municipais às necessidades da população diante de governos estaduais e federal que praticamente deixaram de expandir seus serviços.

Este corpo de idéias e práticas foi crescendo até se constituir numa proposta mais acabada que se denominou PROPOSTA DA REFORMA SANITÁRIA. Esta proposta foi "emprestada" a Tancredo Neves e passou a ser denominada de proposta da Nova República para a área da Saúde. Como se não bastasse a legitimidade da proposta pela sua origem de baixo para cima, através dos vários atores acima citados, houve a consagração máxima na VIII Conferência Nacional de Saúde. Administradores, profissionais e comunidade clamaram por mudanças radicais no nosso sistema de saúde e fecharam a grande proposta que foi sacramentada na Constituição Brasileira e sua Lei Orgânica da Saúde.

Paralelamente a isto, iniciativas governamentais tentavam algumas propostas de alteração do Sistema Único de Saúde. Umas ficaram no projeto preliminar no papel. Outras foram incrementadas como em 1974 o Plano de Pronta Atenção que abriu as portas aos vários convênios de atendimento para que este fosse mais universalizado e ágil. Depois, veio o Pró-Saúde que não chegou a ser implementado e foi logo sucedido pelo Prev-Saúde em sua dezena de versões mas que não chegou a acontecer. O CONASP, plano de menos ambição veio logo a seguir implantando a era das Ações Integradas de Saúde e a Autorização de Internações Hospitalares em substituição à $\mathrm{GIH}$, que tanto foi criticada pela chance fácil de fraude. Gentile dizia que o pagamento por US (como era no tempo da $\mathrm{GIH}$ ) era fonte perene de corrupção, pois dava chance quase que aberta, como um convite à fraude. Depois das AIS em 1983, veio o SUDS em 1987. O SUDS era uma proposta de se unificarem as três esferas de 
governo pelo menos enquanto a Constituição não decretasse e fizesse nascer o SISTEMA ÚNICO DE SAÚDE, o SUS. Não fosse a questão da necessidade de regulamentação, que só foi acontecer com a Lei Orgânica da Saúde no final de 1990, hoje já teríamos contado com 5 anos de implantação do SUS.

\section{O NASCIMENTO DO SUS}

A constituição de 1988 trouxe inúmeras conquistas ao setor saúde, tanto direta como indiretamente. Alguns princípios gerais consagrados nela são essenciais ao Sistema Único de Saúde. Cito apenas três deles: a autonomia dos Estados e Municípios ainda que pertencentes a um Estado federado; o princípio conseqüente da descentralização que rompe com toda a tradição ditatorial militar que enfrentamos durante 25 anos; a valorização da cidadania puxando pela participação popular como mecanismo de controle da sociedade como um todo, tanto do público como do privado.

Além destas questões gerais ainda temos uma outra questão que guarda especificidade com a saúde, mas em conjunto com a previdência e a assistência social. Foi o conceito assumido de Seguridade Social em seu todo, onde estes três setores se juntam e são financiados pelas mesmas fontes de receita, e guiaram os mesmos princípios da igualdade, da universalidade, etc. Passamos do conceito de previdência para aqueles que contribuem (incluindo benefícios, assistência médica e social), para o conceito mais amplo de direitos de cidadania, extensível a todos os cidadãos brasileiros, sem discriminação.

$\mathrm{Na}$ questão específica da saúde os avanços foram enormes. A saúde passa a constituir na Constituição toda uma Secção com vários artigos, o que 
não ocorrera nas Constituições anteriores. Isto representou a grande revolução da saúde. Estes princípios foram melhor explicitados nas Leis 8080 e 8142.

Os princípios norteadores do Sistema Único de Saúde são os seguintes:

- Saúde como direito de todos e dever do Estado, ainda que se conte com a cooperação dos indivíduos, das famílias, da sociedade e das empresas;

- universalidade e eqüidade do acesso;

- fim da dicotomia entre promoção, prevenção, assistência e reabilitação, com ênfase na prevenção;

- integralidade na assistência ao indivíduo;

- gratuidade;

- descentralização com gestor único em cada esfera de governo;

- participação complementar do privado, com preferência para os filantrópicos e os sem fins lucrativos, ainda que a atividade privada seja livre, sob controle do Estado;

- ênfase em algumas áreas como saúde do trabalhador, vigilância epidemiológica, sanitária, alimentação e nutrição, portadores de deficiência;

- participação comunitária efetiva através dos Conselhos de Saúde e das Conferências de Saúde. 
- financiamento tripartite entre a União, Estados e Municípios e através dos recursos da Seguridade Social.

Estes são alguns dos princípios filosóficos e operacionais do Sistema Único de Saúde.

Muita confusão inconsciente ou premeditada tem sido feita em relação ao SUS. A situação cab́tica em que vive o setor saúde neste momento, leva a que muitas pessoas e mesmo autoridades atribuam isto ao SUS. Pelo que foi descrito acima podemos chegar à conclusão de que o SUS ainda não existe, não conseguiu sair do papel. Não se pode responsabilizar pelo CAOS aquilo que nem aconteceu. Numa análise realista, podemos buscar em pelo menos trinta anos de descaso com o social, a verdadeira causa do que aí está. o suS é a resposta que brotou da sociedade, de baixo para cima, até se legitimar dentro da Constituição, para se criar o novo e trazer uma solução para a crise.

\section{O CENÁRIO ATUAL}

A todos que vivemos diuturnamente a questão saúde em nosso país, preocupa sobremaneira o momento presente. Nunca estivemos em situação tão difícil e com chances de saída tão estreitas. $O$ investimento em saúde decrescente. A universalização do atendimento. A miséria atingindo a 32 milhões de brasileiros. $O$ descontrole acumulado de quase uma década de transição na busca de saídas viáveis, não politicamente assumidas pelos que dirigiram o país. Tudo isto e muito mais alicerçou o atual cenário em que vivemos. 
Os reais componentes do caos na saúde aí estão:

1. Aumento da demanda: universalização, desemprego e baixos salários, tornando proibitivo o uso de sistemas complementares.

2. Agravamento da demanda, desemprego, miséria, pobreza e fome gerando mais doenças e agravando as existentes.

3. Encarecimento da assistência: incorporação desordenada de equipamentos, medicamentos e especialização precoce e errônea dos profissionais de saúde.

4. Queda real do financiamento em proporção às necessidades sentidas e acumuladas.

As conseqüências não ficam restritas ao setor saúde. Elas se estendem pelo dia a dia num comprometimento total do meio ambiente e todos seus componentes em que vive o homem brasileiro. As doenças infectocontagiosas se multiplicam, as epidemias surgem incontroláveis. As novas causas de morbi-mortalidade estão aí como os acidentes de trânsito, os acidentes de trabalho, a violência urbana e rural.

O SUS COMO A SAIDA...

A sociedade tem que perceber que existe uma saída legal para tudo isto que aí está. Ela foi descrita acima como preceito constitucional. Ainda não aconteceu, não se implantou. É necessário que, num esforço coletivo, se busque a saída via implantação do SUS. 
A atual equipe dirigente do Ministério da Saúde, tendo à frente o Ministro Jamil Haddad e o Presidente do INAMPS, Carlos Mosconi, desde que assumiu, fez um compromisso com a sociedade: VAMOS IMPLANTAR O SUS. Vamos CUMPRIR E FAZER CUMPRIR A LEI. A vontade política, que até então não existia entre os dirigentes máximos da saúde, se mostra agora férrea. A decisão foi tomada e as providências se encaminham desde dezembro de 1992. Numa atitude democrática, ao invés de, de pronto, lançarem um novo programa através de Diário Oficial, tomaram o partido de discutir amplamente com todas as forças sociais envolvidas. Algumas centenas de reuniões foram realizadas pelo Brasil afora debatendo OS CAMINHOS, para que se aperfeiçoasse o documento e houvesse adesão das instituições e da sociedade à forma de se implantar o SUS. Finalmente após duas reuniões com o Conselho Nacional de Saúde que apresentou propostas e sugestões numa primeira vez e posteriormente aprovou o documento com as modificações já realizadas, parte-se para a concretização da proposta.

O título do documento apresentado pelo Ministério da Saúde é: "A DESCENTRALIZAÇÃO DAS AÇÕES E SERVIÇOS DE SAÚdE - A OUSADIA DE CUMPRIR E FAZER CUMPRIR A LEI". Este documento não pretende inventar nada, acrescentar nada aos princípios constitucionais, apenas os relembra. 0 inovador da proposta reside na coragem de tentar um caminho para que o SUS aconteça. Sua discussão reside no COMO vamos concretizar aquilo que já é preceito legal.

A síntese da proposta é sair do sistema centralizado em que o INAMPS compra serviços em cada rincão deste país, inclusive, inconstitucionalmente, até do sistema público. 
Como descentralizar rapidamente num país de extensão continental, com as 27 realidades diferentes de cada Estado brasileiro e mais de cinco mil municípios? A proposta prevê situação de processo como a saída mais sensata. O processo vai se dar de maneira gradual, adequando-se a cada realidade local, possibilitando que, num retrato, daqui há alguns meses possamos visualizar municípios e Estados em situações diferentes mas, todos a caminho de uma gestão plena em sua esfera de governo. De uma situação incipiente, parte-se para uma descentralização parcial, depois semiplena e plena. Na incipiente os municípios passam a ampliar seu nível de gerenciamento: unidades próprias, unidades estaduais locais, cadastramento dos vários serviços de saúde existentes, autorização de contratos novos, montagem de sua equipe local de planejamento, avaliação e controle.

Numa segunda fase, a parcial, ele assume os contratos com os serviços privados complementares e avaliação completa de todos os serviços de saúde existentes. Na plena temos uma gestão plena.

Cada uma destas fases terá um modelo de financiamento. Nas três primeiras ainda o teto será aquele de produção de serviços, através de série histórica corrigida, levando-se em conta o critério populacional. Ao atingirmos a fase plena o critério possivelmente será outro, podendo-se mesmo, à época, dispor de condições e dados fidedignos para se regulamentar o art. 35 da 8080 . A grande novidade do financiamento é que a partir da fase parcial os recursos serão utilizados pelos municípios num sistema de "vasos comunicantes" entre os recursos alocados para atividades ambulatoriais (SIA-SUS) e aqueles alocados para as internações (SIH-SUS).

Este salto levará a que os municípios, administrando a totalidade de recursos poderão utilizá-los de acordo com as suas prioridades, modificando 0 
modelo assistencial e sendo beneficiados pela administração de possíveis saldos da conta $\mathrm{AlH}$ economizada pela maior ênfase nas atividades promocionais e preventivas em saúde. Na fase parcial, os recursos serão administrados mediante crédito. Na semiplena e na plena, os recursos serão previamente repassados em espécie, no sistema de transferências intergovernamentais fundo a fundo.

Os pré-requisitos para que isto aconteça serão basicamente aqueles da Lei 8142, onde se exige de cada esfera de governo a existência de Conselho de Saúde, Fundo de Saúde, participação com recursos próprios como contra partida, um plano de saúde, um relatório de gestão e o compromisso de investir em recursos humanos através de um plano de cargos, carreira e salários. Tudo devidamente amarrado nos princípios constitucionais e na Lei Orgânica da Saúde.

Para que tudo isto seja viável, na introdução do documento abre-se uma discussão sobre alguns pontos fundamentais sobre os quais devemos trabalhar para que este modelo de descentralização dê certo. Não basta descentralizar para sairmos do caos. Existem princípios da lei que são essenciais para que o SUS aconteça.

\section{AS GRANDES BATALHAS DO MOMENTO ATUAL}

Para que o SUS saia das leis para a realidade devemos estar todos lutando para vencer algumas batalhas que serão, se não vencidas, os verdadeiros empecilhos na concretização do SUS. 


\subsection{O financiamento do SUS}

Impossivel pensarmos um concretizar o SUS sem que, urgentemente discutamos com a sociedade a questão do financiamento do SUS. Com financiamento decrescente e custo crescente a matemática, de antemão, garante que não vai dar certo. $O$ que aconteceu nos últimos anos é que os princípios constitucionais do financiamento do SUS não se concretizaram.

A primeira falha existente é o baixo investimento do governo federal em saúde (menos de $1 \%$ de seu orçamento fiscal), ainda que tenha ficado claro na Constituição que cada esfera de governo deva colocar recursos fiscais para sustentar o orçamento da Seguridade Social. A segunda falha é em relação aos demais componentes de receita da Seguridade Social. 0 que todos nós pensávamos, quando da implantação da idéia de Seguridade Social, é que o Orçamento da Seguridade Social fosse se constituir num grande fundo onde três parceiros iriam buscar recursos indiscriminadamente de acordo com os percentuais históricos de sua necessidade (Saúde 30\%, Previdência $65 \%$ e Assistência Social 5\%). Isto não se deu. A fonte de contribuição de empregados e empregadores foi mais destinada à previdência ficando a saúde com apenas $15 \%$ dela.

A fonte questionada (dinheiro podre) do FINSOCIAL foi mais alocado à saúde numa proporção de mais de 50\%. E assim por diante. Quem definiu assim? baseado em que princípios? De outro lado quem deveria administrar este fundo e distribui-lo seria o Conselho Nacional da Seguridade Social, mas isto não aconteceu e quem administra é o Ministério da Previdência que se acha na autoridade de reter percentuais da saúde e de até mesmo, publicamente, anunciar que nos próximos meses não repassará nada da contribuição de empregados e empregadores à saúde. 
Acima do bem e do mal, e da própria constituição! Isto confirma o que sabíamos: a fragilidade do setor saúde sempre contabilizado à conta das despesas e não do maior dos investimentos: a vida e saúde do homem. Nunca a saúde gozou de prestígio e sempre foi deixada para trás nas negociações essenciais. A última novidade por mim "cantada" há meses atrás está para acontecer: recursos do FINSOCIAL pagos por nós cidadãos, pois incluídos em todas as planilhas de custo e sonegados ou recolhidos em juízo pelos empregadores, são alvo hoje de negociação com estes mesmos empregadores para abaterem nos recolhimentos atuais. Mais uma grande negociata se instaura neste país: recolher dos contribuintes e consumidores, questionar a validade na justiça e se apropriar destes recursos como se próprios fossem!!!

Uma terceira questão: a alocação de uma série de despesas outras que antes nunca tinham sido alocadas em saúde, para usufruírem das receitas da seguridade social, transformando nossos insuficientes $30 \%$ em praticamente apenas $20 \%$. Foi assim que nos últimos anos se colocou na conta da saúde recursos para o IBAMA, CIACs, Hospitais Universitários, Sistemas de Saúde próprios dos trabalhadores federais de outros ministérios, saneamento básico do Ministério de Ação Social e outros.

A quarta questão: os recursos fiscais de Estados e Municípios não estão entrando suficientemente na conta. Os municípios que assumiram sua responsabilidade têm investido até $30 \%$ de seus orçamentos próprios em saúde. Outros Estados e municípios, ao receberem recursos federais deixam quase que automaticamente de recolher seus próprios recursos.

Aí estão as causas principais da falta de recursos. Some-se a isto o estado de desobediência civil em que se mergulha a sociedade que não confia no governo: para cada cruzeiro arrecadado deixa-se de arrecadar 1,2 cruzeiros. No 
FINSOCIAL a sonegação é mais vergonhosa: para cada cruzeiro arrecadado deixase de arrecadar 2,8 cruzeiros!!!...

A saída financeira depende de aumento dos recursos pelas vias acima descritas e um melhor aproveitamento dos poucos e parcos recursos existentes. A corrupção tem consumido, por estimativa, entre 30 e $40 \%$ dos recursos. Ainda se perde por mau uso, por uso indevido, por um modelo assistencial inadequado, por baixo investimento em recursos humanos (encarece a assistência pelo descompromisso de horário, tarefa, uso errado de equipamentos e medicamentos, etc., etc.).

\subsection{O modelo assistencial}

Tem que haver uma grande discussão envolvendo a sociedade, os profissionais de saúde e os administradores dos serviços de saúde sobre o modelo assistencial que estamos praticando.

Toda vez que se levanta esta questão os patrulheiros de plantão se enchem de uma santa indignação e bradam que isto é defender uma medicina de pobre para pobre e de rico para rico. Isto é nivelar por baixo. Nada melhor para arrefecer os ânimos que buscar subsídios em dados concretos. A medicina cujo modelo teimamos em imitar, a norte-americana, tem gasto 3.250 dólares "per capita" só em saúde (quase o dobro de nosso PIB "per capita"...) e ainda deixa sem assistência 40 milhões de norte-americanos. Nem de longe, no computo mundial, figura ele como o melhor tipo de assistência. Há países do mundo fazendo melhor medicina e gastando a metade destes recursos "per capita", como o Canadá. E nós? Podemos colocar os pés no chão e ver o modelo que nos é possível enquanto tivermos pouco mais de 2000 dólares "per capita" para 
cuidar de todas as nossas necessidades: alimentação, transporte, habitação, educação, vestuário, cultura, lazer, etc., etc.?

Teimaremos ainda por muito tempo em lutar contra um modelo: hospitalocêntrico, medicamentalizado, baseado em especialistas e equipamentos sofisticados (alguns deles proibidos ou fora de uso em seus países de origem)? Corremos o risco de não discutirmos isto urgentemente com nossos concidadãos e cristalizarmos, aí sim, uma medicina para pobres e outra para ricos, esta financiada por cidadãos de segunda categoria!...

0 modelo que defendemos é aquele que se mostre mais resolutivo e que seja social e tecnicamente aceito pela sociedade e que possa ser sustentado pela nossa economia. Sem estes três componentes qualquer modelo que buscamos não terá a mínima chance de ser universalizado e buscar a eqüidade que nada mais é que a justiça.

\subsection{Os recursos humanos}

Neste componente reside o grande problema atual da saúde e de outro lado o único caminho para se chegar à solução.

O quadro enfrentado é de profissionais insatisfeitos devido à má remuneração e falta de condições de trabalho. Muitos deles despreparados, com especialização precoce e inadequados ao desempenho de suas funções principalmente nos serviços básicos de saúde. Ainda resta uma questão principal: o conhecimento de nossa realidade, das propostas do setor saúde, do seu inserir-se na sociedade, de seu comprometimento com as pessoas e com a sociedade. O modelo liberal sonhado na infância, no vestibular e na faculdade 
nada tem a ver com a realidade do dia-a-dia de nosso país. Além da decepção, alguns se enchem de revolta que é descarregada no próprio exercício profissional.

O novo modelo assistencial pretendido pelo SUS tem em seu bojo a proposta de envolvimento dos profissionais de saúde, valorizando seu trabalho através de um Plano de Cargos, Carreira e Salário justo, com aprimoramento continuado não só no campo do conhecimento médico, mas na parte filosófica de um sistema de saúde e nas relações humanas que levem ao comprometimento de todos com a sociedade.

\subsection{O controle social}

A Constituição é rica em defesa da participação dos cidadãos e em garantir-lhes inúmeros direitos, como co-partícipes de nossa nação.

Cada dia nos convencemos mais que a cidadania é o maior direito, que temos todos a defender. É a situação que primeiro nos iguala a todos, independente de qualquer outro predicado. Transitoriamente trabalhadores, transitoriamente profissionais mas sempre CIDADÃOS.

Os mecanismos constitucionais de participação da sociedade e do exercício do controle social são genéricos e específicos. Os genéricos estão em medidas judiciais como o mandato popular e outros, a defesa do consumidor, com seu código posterior, o direito a informações, o uso do legislativo como um todo e de suas várias comissões.

Para a área específica de saúde foram garantidos três outros mecanismos específicos. O Ministério Público que tem que zelar pelos setores considerados de relevância pública e foi só a saúde que conseguiu esta 
qualificação na Constituição. Os Conselhos de Saúde com sua formação paritária: de um lado cidadãos usuários e de outro administradores, prestadores e trabalhadores de saúde, com seu caráter deliberativo e sua competência inclusive na auditoria financeira. Para auscultar a comunidade criou-se o grande fórum que são as Conferências de Saúde, municipais, estaduais e nacional.

Estes mecanismos todos precisam ser divulgados e utilizados pelos cidadãos. Infelizmente a submissão foi uma das nossas características de povo durante muitos séculos e precisamos mudar, descruzar nossos braços, parar de achar que surgirão salvadores da pátria para modificar nossa situação, ou em quem poderemos sempre colocar a culpa por tudo que acontece.

Os novos tempos do SUS clamam por uma maior e mais profunda participação popular ocupando os lugares reservados pelas leis e trabalhando para transformar esta nossa realidade extremamente iníqua.

\section{CONCLUSÃO}

Este é o momento atual do SUS. Esta é a saída legal para que transformemos nossa realidade. Necessário se faz que a sociedade, numa Santa Aliança (pacto social já está desgastado), faça com que o SUS seja implantado, saia do papel e se torne realidade. Não apenas uma realidade gerencial, pela descentralização, pela gestão plena, mas tendo isto como ferramenta para se conseguir o principal: melhores condições de VIDA E SAÚDE PARA TODOS OS CIDADÃOS BRASILEIROS. 